Neoliberalism as the Cause of Underachievement

\title{
STATE DOWNSIZING AS A DETERMINANT OF INFANT MORTALITY AND ACHIEVEMENT OF MILLENNIUM DEVELOPMENT GOAL 4
}

\author{
Marco Antonio Palma-Solís, Carlos Álvarez-Dardet Díaz, \\ Álvaro Franco-Giraldo, Ildefonso Hernández-Aguado, \\ and Santiago Pérez-Hoyos
}

\begin{abstract}
The aim of this study was to evaluate the worldwide effect of state downsizing policies on achievement of U.N. Millennium Development Goal 4 (MDG4) on infant mortality rates. In an ecological retrospective cohort study of 161 countries, from 1978 to 2002, the authors analyzed changes in government consumption (GC) as determining exposure to achievement of MDG4. Descriptive methods and a multiple logistic regression were applied to adjust for changes in gross domestic product, level of democracy, and income inequality. Excess infant mortality in the exposed countries, attributable to reductions in GC, was estimated. Fifty countries were found to have reduced GC, and 111 had increased GC. The gap in infant mortality rate between these groups of countries doubled in the study period. Nonachievement of MDG4 was associated with reductions in GC and increases in income inequality. The excess infant mortality attributable to GC reductions in the exposed countries from 1990 to 2002 was 4,473,348 deaths. The probability of achieving MDG4 seems to be seriously compromised for many countries because of reduced public sector expenditure during the last 25 years of the 20th century, in response to World Bank/International Monetary Fund Washington Consensus policies. This seeming contradiction between the goals of different U.N. branches may be undermining achievement of MDG4 and should be taken into account when developing future global governance policy.
\end{abstract}

International Journal of Health Services, Volume 39, Number 2, Pages 389-403, 2009 (c) 2009, Baywood Publishing Co., Inc.

doi: 10.2190/HS.39.2.i

http://baywood.com 
Infant mortality in countries throughout the world is determined by a range of living-condition variables: poverty $(1,2)$; unemployment $(3,4)$; economic barriers such as income, prices (5), and payment of medical services (6); housing conditions such as location (7) and cleanliness (5); illiteracy (8); mother's level of education $(9,10)$; racial $(11)$ and ethnic (12) discrimination; access to services such as health (5), water (13), electricity (14), environmental sanitation, and credit (5); and land availability (5). Clearly, infant/child mortality rates are not linked to a single factor but are affected by multiple manifestations of a disadvantaged population's living conditions - particular or structural determinants for the World Health Organization Social Determinants of Health (15), and particular determinants for Breilh (16) - which have a hierarchical and interdependent relationship with other "general or socioeconomic and political" factors that, in turn, determine them. Different studies of this level of determinants have demonstrated that infant/child mortality is associated with a country's dependency situation (17), level of democracy (18), governing party's public policy (19), structural adjustments (20), neoliberal economic development (21), social classes (22), level of economic transfers from the state to the population (11), level of economic inequality $(23,24)$, and gross domestic product $(14,25)$.

Interrelations and hierarchies also exist at this general level of determinants. Economic models and ideologies act as universal determinants that establish social classes, generate income inequality, build democracy, organize governments, and dictate social development policies. Country dependence, structural adjustments, and government distributive and redistributive functions (i.e., economic transfers) derive from general determinants and mediate between the levels of general and particular determinants.

Gross domestic product (GDP) is a synthetic measure of overall economic activity (26), estimated from income and/or production, that is frequently used as a general epidemiological determinant under the assumption that the production of national wealth is a universal factor. In the prediction of health problems, GDP has been useful because it has been linked to a population's level of health. However, it can obscure the participation of any one of its constitutive elements in these associations, because it encompasses different groups of income and outcome (e.g., domestic consumption, government consumption, gross capital formation, imports and exports). In addition, any increase or decrease in government consumption, or any of its components, can be expected to have repercussions in the GDP.

Economic inequality originates in a country's economic model and shapes the specific way its population relates to and participates in the production, distribution, and consumption of goods and services. Use of democracy plays a significant role in organizing a country's population to make decisions and implement actions that can eliminate, limit, or diminish social inequalities such as economic disparities. It therefore has potential and real effects on a population's living conditions. 
During the final quarter of the 20th century, the World Bank and the International Monetary Fund (IMF) adopted a series of economic policies currently known as the "Washington Consensus" $(27,28)$ and largely acknowledged as a package of "neoliberal" reforms. These were originally designed to lower inflation rates, stabilize currencies, and foment mechanisms to improve the operation of multinational companies (29).

The neoliberal economic model subsequently expanded throughout the world, replacing socialist and Keynesian capitalist models (30). Poverty and inequality obviously existed prior to promulgation of the neoliberal model, but they undoubtedly have worsened and expanded under it. An essential element of this model for national economic reform is a reduction in government consumption and the state's role in economic matters.

The effects of these reforms have been particularly notable in contexts in which income inequalities are extreme, because they lead to reductions in government economic transfers to the population, thus exacerbating the already challenging situation of disadvantaged social sectors. This transformation can affect much or even all of the government support provided through economic transfers to the population, including health, education, social protection, employment, credit, sanitation, and social security. Many of these functions are then transferred to the private sector through services liberalization or privatization, forcing the population to increase its spending to cover services previously covered by the government. Ever since its creation, these aspects of the Washington Consensus have been criticized for their potentially negative effects on health (31), although its proponents claim it will provide long-term benefits.

In September 2000, all 189 member countries of the United Nations adopted the Millennium Declaration and agreed to attain its goals by 2015 (32). To meet the Millennium Development Goals (MDGs), developing countries must reach organizational and action agreements with developed countries ( $\sim 20$ countries), in which the former commit to reorganizing and implementing actions required for their development (i.e., to meet the MDGs), while the latter commit to contributing the necessary economic and/or technical resources.

Both the MDGs and the World Bank/IMF approaches have the assumed intention of improving worldwide living conditions. The MDGs are designed to achieve this end by focusing on reducing social inequalities through the economic, technical, and organizational support of international institutions and developed countries $(33,34)$. The neoliberal World Bank/IMF method is trying to promote worldwide economic development through application of a model emphasizing private profits and reduction of state economic intervention (also known as "state downsizing") - in other words, the removal of states from the economic management and decision-making processes that affect countries' development.

The MDGs are clearly oriented toward developing countries, but meeting these goals requires a global vision because they will be the product of advances in all countries. Also, the declared goals, such as a two-thirds reduction in infant/child 


\section{2 / Palma-Solis et al.}

mortality, are calculated based on projections and future scenarios that include all countries. Health is central to the MDGs and is explicit in Goal 4 (MDG4), the 66 percent reduction in infant/child mortality by 2015 compared with 1990 levels. Progress toward this goal so far is hardly heartening, and if current conditions persist the goal will not be met in sub-Saharan Africa, South Asia, the Arab states, Latin America. and central and eastern Europe (35).

Obstacles to meeting the MDGs have mainly been identified in relation to poverty (34), although there remains an acute lack of knowledge on the political determinants of poverty and its accompanying health consequences in many countries (36). Among the few empirically studied political determinants, welfare state social policy (37) and level of democracy (18) have been deemed as influencing a country's level of health. In an increasingly globalized world, the policies that countries adopt (e.g., in health care) can be strongly affected by macro-trends at the transnational level (38), including the macroeconomic policies promoted by international organizations such as the World Bank and IMF.

This study explores the hypothesis that state downsizing during the last 25 years of the 20th century, as a consequence of the Washington Consensus, has negatively affected infant mortality rates and therefore hindered the possibility of attaining MDG4 by 2015 .

\section{MATERIAL AND METHODS}

\section{Study Design}

An ecological cohort design was used, with countries as the unit of observation and analysis, to monitor all countries in the world in the period 1978-2002. The exposure variable was change in government consumption (GC), the outcome was achievement of MDG4, and changes in GDP, Gini index, and Freedom ratings were taken into account as potential confounders.

\section{Study Period}

The year 1978 was used as the starting point because worldwide neoliberal economic reforms began in the mid-1980s. This provides pre-reform data to compare with post-reform data and thus highlight the possible effects on infant mortality. Five-year periods were used to provide observation points for the evolution of infant mortality over the study period, as well as any associated variables.

Data and Sources

A database was built that included all countries with available data for the selected time period. The MDG4 has three proposed indicators: under-five mortality, 
infant mortality, and percentage of children immunized against measles. Infant mortality rate (IMR) was chosen as the health outcome variable, and data were taken from the WHO statistical information system (39). Data on total number of live births by country were from the Demographic Yearbook (40). Data for macroeconomic variables such as GC and GDP were from the U.N. statistical system (41), and the Gini index was obtained from the World Bank (42, 43). Population data from the Census Bureau International Data Base (44) were used to calculate per capita GDP (GDPpc) and per capita GC (GCpc). Freedom ratings were obtained from Freedom House (45) and treated as a proxy indicator of a country's level of democracy. The above data were then analyzed to compare changes in the value of each variable at the beginning and end of each five-year period, as well as between the 1978 baseline data and the final 2002 data.

\section{Variables Stratification}

Countries with decreases in GCpc during the study period were classified as the cohort of "exposed" countries, while those with increases or no changes were classified as the cohort of "unexposed" countries. Projected trends were then generated for IMR in each country by linking the 1990 rate to a level one-third of that rate in 2015 (i.e., MDG4). This was then compared with the actual observed rate between 1978 and 2002. Based on the outcome, the countries were divided into two groups: those with rates less than the mean rate in $2002(=0)$ and those with rates higher than the mean $(=1)$.

Changes in per capita GDP (constant dollar value) during the study period were used to classify countries as having either an increasing or decreasing GDP. The Gini index, based on income distribution between households, is a standard measure providing an overall estimate of inequality in a range of 0 to 1 , with 1 being the most unequal. Each country's Gini index data for 1978-2002 were used to classify them as having increasing or decreasing inequality. Freedom level is a political rights and civil liberties index begun in 1978 by Freedom House, which gives countries a rating between 1 and 7, with 1 representing the highest and 7 the lowest level of freedom. The average index values were then used to assess each country's level of freedom by comparing its ratings between 1978 and 2002 and then classifying it as having either a higher or lower level of freedom.

\section{Data Analysis}

Descriptive Analyses. (a) Estimations of mean GCpc, overall IMR, their gradients, and changes in these gradients for "exposed" and "unexposed" countries, using GC in the five-year periods between 1978 and 2002:

- Government consumption per capita gradient $(\mathrm{GCg})=$ GCpc unexposed GCpc exposed 


\section{4 / Palma-Solis et al.}

- Infant mortality rate gradient $(\mathrm{IMRg})=$ IMR unexposed - IMR exposed

- Government consumption per capita gradient change $(\mathrm{GCgc})=(\mathrm{GCg} 1$, $\mathrm{GCg} 2, \mathrm{GCg} 3 \ldots \mathrm{GCg} n-\mathrm{GCg} 1) /(\mathrm{GCg} 1) \times 100$

- Infant mortality rate gradient change (IMRgc) $=($ IMRg1, IMRg2, IMRg3 . . $\operatorname{IMRg} n-\operatorname{IMRg} 1) /(\operatorname{IMRg} 1) \times 100$

(b) Estimations for the overall study period (1978-2002) of the mean of each independent variable (GCpc, GDPpc, Gini index, and Freedom index), as well as the weighted IMR of the country groups with IMR below or above the approximate 2002 MDG4 rate.

Effects Measurement and Confounding Control. The dependent variable was split into two categories, MDG4 achieved or MDG4 not achieved, to measure the effect of reductions in GCpc on IMR, and an odds ratio (OR) used to measure association, with $95 \%$ confidence intervals $(95 \% \mathrm{CI})$, in a bivariate logistic regression analysis. A non-conditional multivariate logistic regression analysis was also done to control for the potential confounding effect of changes in GDPpc, Gini, and Freedom level or to explore for effect impact.

Measures of Potential Impact. The number of infant deaths attributable to reductions in GCpc was calculated by first estimating the proportion of infant mortality attributable to reductions in GCpc for exposed countries with the adjusted odds ratio: $(\mathrm{OR}-1) / \mathrm{OR}$. The excess of infant deaths in countries that reduced their GCpc was then calculated by subtracting the number of infant deaths expected if MDG4 were achieved from the number of observed infant deaths. Because the MDG calculation baseline is 1990, attributable infant deaths were estimated for 1990-2002. The difference in the number of calculated infant deaths for each year was then multiplied by the attributable proportion to produce a worldwide estimation for infant deaths attributable to reductions in GCpc for each year. Finally, excess infant deaths for all the years were summed to determine the total number of attributable infant deaths for 1990-2002.

\section{RESULTS}

A total of 161 countries, representing 83.4 percent of U.N. membership and 96 percent of world population, were included in the analysis. Average GCpc in countries with increases (111 countries) rose steadily to a peak in 1991. Countries with decreases in GCpc (50 countries) exhibited an initial upward trend to 1981, which then decreased continually until recent years (Figure 1). The gap between the two groups has expanded since 1981.

A comparison of IMR for 1978-2002 with average GCpc figures for the same period shows IMR to be higher in countries with reductions in GCpc (i.e., exposed countries). In these exposed countries, IMR decreased by 29 percent, 
State Downsizing and Millennium Development Goal 4 / 395

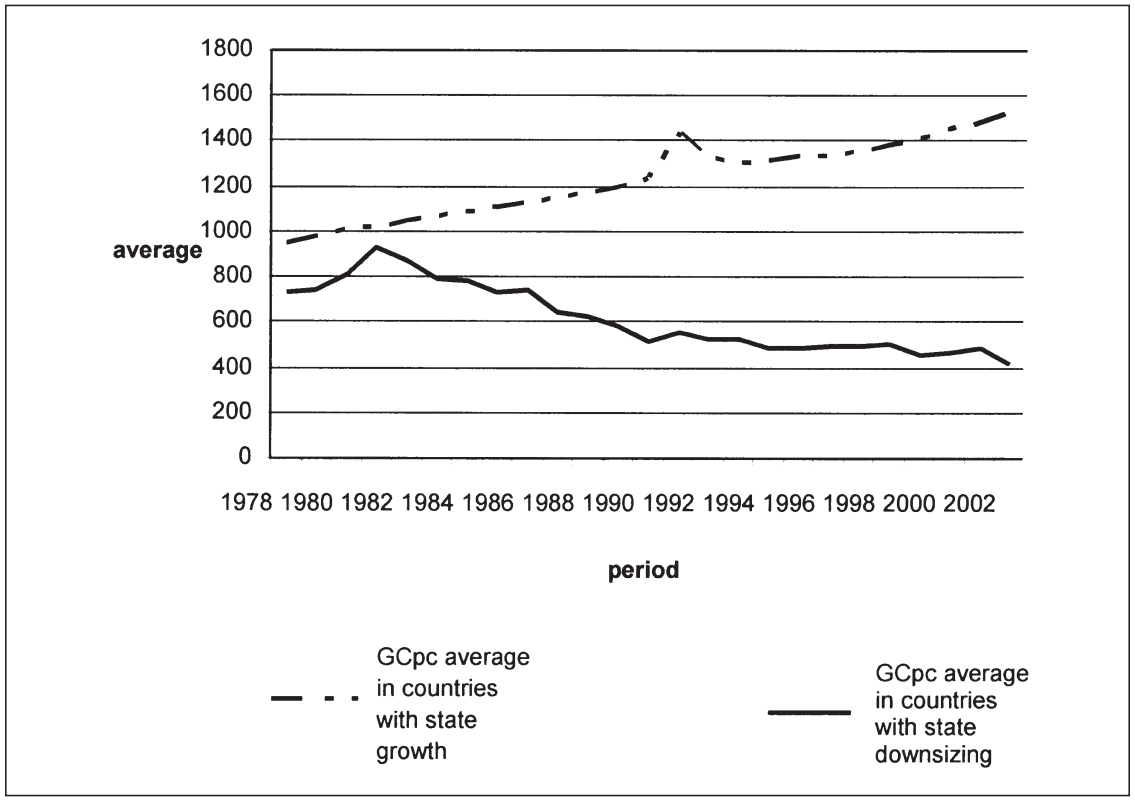

Figure 1. Time trend of per capita government consumption ( $\mathrm{GCpc}$ ) averages, constant 1990 dollars, in countries with (50 countries) or without (111 countries) state downsizing, 1978-2002.

but in unexposed countries it decreased by 42 percent (Table 1). The resulting gap in IMR between exposed and unexposed countries widened from 19 per 1,000 in 1978 to 25 per 1,000 in 2002.

The position of each country with respect to the MDG4 adjusted for 2002 shows that those best positioned to attain the goal are those with the highest GCpc, GDPpc, and Freedom level, and lowest Gini index (lowest inequality), both in absolute figures and in change values between 1978 and 2002 (Table 2). Countries that appear unlikely to meet the MDG4 have reductions in GCpc and increases in income inequality.

Overall, 63 of the 161 analyzed countries will probably not achieve MDG4, if their present trends continue. Bivariate analysis for the 1978-2002 period showed statistically significant associations between meeting MDG4 and changes in GCpc $(\mathrm{OR}=4.55 ; 95 \% \mathrm{CI}, 2.23-9.28)$, in GDPpc $(\mathrm{OR}=3.72 ; 95 \% \mathrm{CI}, 1.81-7.66)$, and in Gini $(\mathrm{OR}=3.81 ; 95 \% \mathrm{CI}, 1.63-8.89)$, but not for changes in Freedom level. The multivariate logistic regression model indicated that change both in GCpc and in the Gini were statistically significant in explaining IMR, with adjusted OR values of $4.23(95 \% \mathrm{CI}, 1.46-12.21)$ for change in $\mathrm{GCpc}$ and 3.66 (95\% CI, 1.43-9.36) for change in the Gini. Changes in GDPpc were not 
396 / Palma-Solis et al.

Table 1

Per capita government consumption and infant mortality rates in countries exposed and unexposed to state downsizing: gradients construction among 161 countries, 1978-2002

\begin{tabular}{lrrrrrr}
\hline Exposure and gradient $^{a}$ & 1978 & 1983 & 1988 & 1993 & 1998 & 2002 \\
\hline Unexposed & & & & & & \\
$\quad$ Government consumption per capita & 682.8 & 719.6 & 777.9 & 816.1 & 822.6 & 890.8 \\
$\quad$ Infant mortality rate & 85.1 & 73.5 & 65.5 & 57.8 & 53.3 & 49.4 \\
& & & & & & \\
Exposed & & & & & \\
$\quad$ Government consumption per capita & 366.5 & 350.7 & 272.3 & 230.7 & 227.7 & 203.6 \\
$\quad$ Infant mortality rate & 103.9 & 92.3 & 85.6 & 79.8 & 73.8 & 74.7 \\
& & & & & & \\
Gradient & & & & & & \\
$\quad$ Government consumption per capita & 316.4 & 368.9 & 505.6 & 585.4 & 594.9 & 687.2 \\
$\quad$ Infant mortality rate & -18.8 & -18.8 & -20.1 & -22.0 & -20.5 & -25.3 \\
& & & & & & \\
Gradient change & & & & & & \\
$\quad$ Government consumption per capita & 0.0 & 16.6 & 59.8 & 85.0 & 88.1 & 117.2 \\
$\quad$ Infant mortality rate & 0.0 & 0.0 & 6.8 & 16.7 & 9.1 & 34.7 \\
\hline
\end{tabular}

Source: U.N. statistical system and WHO.

${ }^{a}$ Gradient: subtractions: unexposed - exposed. Gradient change: (y1, y2, y3 $\left.\ldots \mathrm{y} n-\mathrm{y} 1\right) /(\mathrm{y} 1) \times 100$.

statistically significant $(\mathrm{OR}=2.69 ; 95 \% \mathrm{CI}, 0.84-8.58)$. The adjusted $\mathrm{OR}$ for the association between reductions in GCpc and achievement of MDG4 showed the attributable proportion of IMR in exposed countries to be 76.4 percent. Overall attributable infant deaths increased from 11,834 in 1991 to 893,600 in 2002, with a total of $4,473,348$ infant deaths attributable to reductions in GCpc from 1990 to 2002 (Table 3).

\section{DISCUSSION}

The possibility of achieving the U.N. Millennium Development Goal 4 on infant mortality has apparently been seriously weakened in many countries by reductions in the public sector (i.e., state downsizing) undertaken as part of neoliberal economic reforms during the last 25 years of the 20th century, as well as by increasing intracountry inequality. These countries paid a stiff toll in terms of human mortality and suffering (almost 4.5 million attributable infant deaths from 1991 to 2002) and one that merits attention. During these same 25 years, the World Bank and the IMF strongly advocated and fueled state downsizing 
Table 2

fant mortality rates, macroeconomics, and political variables in 161 countries achieving or not achieving Millennium Development Goal 4 in 2002, 1978-2002

\begin{tabular}{|c|c|c|c|c|}
\hline Variable $^{a}$ & Year and change & $\begin{array}{c}\text { Countries } \\
\text { achieving goal }\end{array}$ & $\begin{array}{l}\text { Countries not } \\
\text { achieving goal }\end{array}$ & Total \\
\hline \multirow{3}{*}{ IMR } & 1978 & 51.6 & 121.7 & 87.9 \\
\hline & 2002 & 26.9 & 74.7 & 54.4 \\
\hline & $\%$ change $1978-2002$ & -47.8 & -38.6 & -38.1 \\
\hline \multirow[t]{3}{*}{ GCpc } & 1978 & $1,337.1$ & 154.3 & 879.2 \\
\hline & 2002 & $1,837.3$ & 152.3 & $1,185.1$ \\
\hline & $\%$ change $1978-2002$ & 37.4 & -1.3 & 34.8 \\
\hline \multirow[t]{3}{*}{ GDPpc } & 1978 & $7,145.9$ & 766.7 & $4,670.7$ \\
\hline & 2002 & $10,010.3$ & 850.6 & $6,480.8$ \\
\hline & $\%$ change $1978-2002$ & 40.1 & 10.9 & 38.8 \\
\hline \multirow[t]{3}{*}{ Gini index } & 1978 & 39.8 & 44.3 & 41.5 \\
\hline & 2002 & 39.5 & 45.9 & 42.0 \\
\hline & $\%$ change $1978-2002$ & -0.7 & 3.7 & 1.1 \\
\hline \multirow{3}{*}{$\begin{array}{l}\text { Freedom } \\
\text { index }\end{array}$} & 1978 & 3.5 & 5.2 & 4.2 \\
\hline & 2002 & 2.8 & 4.4 & 3.4 \\
\hline & $\%$ change 1978-2002 & -18.9 & -15.6 & -17.5 \\
\hline \multicolumn{2}{|c|}{ No. of countries } & 98 & 63 & 161 \\
\hline
\end{tabular}

Sources: U.N. statistical system, WHO, World Bank, and Freedom House.

${ }^{a} \mathrm{IMR}$, infant mortality rate (per 1,000), adjusted rate; other variables, sample mean. GCpc, per capita government consumption; GCPpc, per capita gross domestic product.

policies. Both agencies are part of the U.N. institutional conglomerate, highlighting a political paradox that needs to be considered when developing future global governance policy.

Most analyses associate IMR with a country's wealth and income distribution. Health care or education expenditures, the existence of social inequalities, public sector involvement as a percentage of GDP, and the level of democracy have also been linked to IMR $(8,11)$. The present data highlight the association between income inequality and a country's probability of attaining MDG4, adding further weight to the effect of inequality (46) over that of economic growth indicators.

The intent in the present analysis was to determine whether the hypothesis that neoliberal reforms and structural adjustments have adverse effects on health 
398 / Palma-Solis et al.

Table 3

Infant deaths attributable to reduction in government consumption in 50 countries, 1990-2002

\begin{tabular}{|c|c|c|c|c|}
\hline Year & $\begin{array}{c}\text { Observed } \\
\text { infant deaths } \\
\text { A }\end{array}$ & $\begin{array}{l}\text { Expected infant } \\
\text { deaths (MDG4 } \\
\text { in 2002) } \\
\text { B }\end{array}$ & $\begin{array}{c}\text { Infant death } \\
\text { excess }(A-B) \\
C\end{array}$ & $\begin{array}{c}\text { Infant death } \\
\text { attributable to GCpc } \\
\text { reduction }(\mathrm{C} \times 0.764)^{a} \\
\mathrm{D}\end{array}$ \\
\hline 1990 & $8,131,097$ & $8,131,097$ & 0 & 0 \\
\hline 1991 & $7,929,758$ & $7,914,268$ & 15,490 & 11,834 \\
\hline 1992 & $7,728,419$ & $7,697,439$ & 30,980 & 23,669 \\
\hline 1993 & $7,527,080$ & $7,480,609$ & 46,471 & 35,504 \\
\hline 1994 & $7,422,966$ & $7,263,780$ & 159,186 & 121,618 \\
\hline 1995 & $7,318,851$ & $7,046,951$ & 271,900 & 207,732 \\
\hline 1996 & $7,214,737$ & $6,830,122$ & 384,615 & 293,846 \\
\hline 1997 & $7,110,623$ & $6,613,292$ & 497,330 & 379,960 \\
\hline 1998 & $7,006,508$ & $6,396,463$ & 610,045 & 466,074 \\
\hline 1999 & $6,929,576$ & $6,179,634$ & 749,942 & 572,956 \\
\hline 2000 & $6,852,644$ & $5,962,805$ & 889,839 & 679,837 \\
\hline 2001 & $6,775,711$ & $5,745,975$ & $1,029,736$ & 786,718 \\
\hline 2002 & $6,698,779$ & $5,529,146$ & $1,169,633$ & 893,600 \\
\hline Total & $94,646,750$ & $88,791,582$ & $5,855,168$ & $4,473,348$ \\
\hline
\end{tabular}

Sources: U.N. statistical system, WHO.

Note: MDG4, Millennium Development Goal 4; GCpc, per capita government consumption.

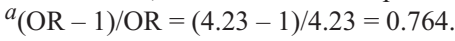

(represented here by IMR) on a worldwide scale could be supported by empirical data (47). Using an ecological retrospective cohort analysis, the only feasible way of testing this hypothesis, we made an estimate of the effect of reducing government consumption in terms of IMR. The credibility of this estimate is founded on the potential determinant relationship between state downsizing and achievement of MDG4. This relatively new way of addressing public health determinants is based on the Commission on Social Determinants of Health (CSDH) framework (15) and on previous research by Jaime Breilh (16), whose analysis of epidemiological determinants focused on protective and deleterious factors. The association described in our study encompasses political and macroeconomic aspects of the CSDH framework by focusing on the effects of macroeconomic policy in the welfare state on epidemiological conditions. The CSDH framework identifies five elements of the social and political context acting to create health determinants: $(a)$ governance, $(b)$ macroeconomic policies, (c) social policies (labor, housing), (d) other public policies, especially health, 
education, and social protection, and (e) cultural and social values. These five elements could be used to further explain the pathways of action of the findings in this study. Government consumption shapes both the direction and the strength of a country's public policies, and the level of inequality is also related to the redistributive nature of these policies and the social and cultural values prevalent in a particular country. Chung and Muntaner (48) carried out a similar kind of typologically multilevel analysis with data from developed countries. Consistency in this type of analysis and support for the present results will probably develop as further research is done employing this approach.

One potential limitation in the present analysis is the lack of data for 23 countries during the study period; many only began collecting data on the selected variables in 1990. The missing data may be relevant, as they include transition countries that experienced drastic changes in government consumption and declining health status caused by the collapse of communist/socialist governments in central and eastern Europe. Any potential bias is unlikely to be large enough to affect the principal conclusions; indeed, these countries experienced significant public sector reductions and reported negative changes in health indicators. As is the case with any analysis using data from multiple sources, data quality can also prove a limitation. United Nations' health statistics (e.g., infant mortality rate) are estimates based on data collected from different sources and using various methods: they are not real data. However, these statistics are the only source available for testing the hypothesis on a worldwide basis and come from the same databases currently used by the United Nations to measure progress toward the MDGs.

The present study involved a much broader analysis of government policies and health than have previous studies, in terms of the variables used, analytical methodology, number of countries studied, and follow-up duration.

Use of GCpc as a proxy estimate of government effort is a more comprehensive measure than health care expenditure (49) or public expenditure as a percentage of GDP. Also, use of the maximum likelihood ratio in the logistic regression models applied here maximized the influence of all the variables included in the analysis (e.g., GDP, GC, democracy, inequalities).

Previous findings of a null effect for government expenditure on health (50) may be explained by the fact that health is determined by multiple factors, not just health care expenditure. Government consumption, in contrast, is a general determinant that affects multiple aspects of disadvantaged populations' living conditions, such as education, sanitation, general services, employment, social security, and public safety. The present results demonstrate that government policy resulting in reductions in social expenditure is determinant at this level.

As critics of the Washington Consensus have pointed out since the resulting policies were initially implemented, reductions in the financial role of government have had important, albeit avoidable, adverse effects in terms of human health. These effects have been felt most in diminished support for social programs aimed 
at the most vulnerable sectors of society and in a lessened redistributive role of the state. Specific actions can be implemented under these conditions to partially mitigate their effects; for instance, clinical interventions at the community level for newborn babies and primary health care for mothers are cost effective in reducing infant mortality (51). However, no lasting solution is possible without broad, multisectoral, public health actions addressing malnutrition, access to safe water, sanitation, indoor air quality, and poverty reduction (52), which can only be put in motion by government policy decisions.

In recent years, the concept of social determinants of health has entered into common use in medicine and public health, a trend reinforced by the WHO's creation of the Commission on the Social Determinants of Health. For research in this area to have any impact on policy development, it needs to focus not on what the social determinants of health are, but on what the causes of these social determinants are. This means considering the policy decisions underlying the social construction of inequality, the forces driving these decisions at various levels, and the consequent effects on health $(53,54)$.

\section{CONCLUSION}

The effectiveness of worldwide social development policy as represented by the Millennium Development Goals is being weakened by the effects of neoliberal economic development policy, specifically in terms of government participation in social expenditure. Reductions in government social expenditure have been accompanied by increased economic inequality and have compromised the ability of many countries to meet Millennium Development Goal 4 on infant mortality.

Acknowledgments - Colleagues from the Public Policies and Health Observatory, including Maria Teresa Ruiz, Airton Stein, Carmen Vives, and Diana Gil, contributed valuable suggestions to the preparation of the drafts, and we are also grateful to John Lindsay for helping us with the English-language version of the manuscript.

\section{REFERENCES}

1. Wagstaff, A., et al. Child health: Reaching the poor. Am. J. Public Health 94(5): 726-736, 2004.

2. Houweling, T. A., et al. Determinants of under-5 mortality among the poor and the rich: A cross-national analysis of 43 developing countries. Int. J. Epidemiol. 34(6):1257-1265, 2005.

3. Frank, R. Los años de la crisis: An examination of change in differential infant mortality risk within Mexico. Soc. Sci. Med. 59(4):825-835, 2004.

4. Tukiendorf, A., et al. Infant mortality-Gynaecological and unemployment aspects in Opole Province, Poland. Cent. Eur. J. Public Health 15(1):7-12, 2007. 
5. Singh, G., and Kogan, M. Persistent socioeconomic disparities in infant, neonatal, and postneonatal mortality rates in the United States, 1969-2001. Pediatrics 119(4): 928-939, 2007.

6. James, C., et al. Impact on child mortality of removing user fees: Simulation model. BMJ 331:747-749, 2005.

7. Donoso, E. Desigualdad en mortalidad infantil entre las comunas de la provincia de Santiago. Rev. Med. Chil. 132(4):461-466, 2004.

8. Szwarcwald, C. L., Bastos, F. I., and Andrade, C. L. Medidas de desigualdad en salud: la discusión de algunos aspectos metodológicos con una aplicación para la mortalidad neonatal en el Municipio de Río de Janeiro, 2000. Cad. Saude Publica 18(4):959-970, 2002.

9. Houweling, T. A., et al. Mortality inequalities in times of economic growth: Time trends in socioeconomic and regional inequalities in under 5 mortality in Indonesia, 1982-1997. J. Epidemiol. Community Health 60(1):62-68, 2006.

10. Schell, C. O., et al. Socioeconomic determinants of infant mortality: A worldwide study of 152 low-, middle-, and high-income countries. Scand. J. Public Health 35(3):288-297, 2007.

11. Junqueira, V., et al. Equidad en la salud: evaluación de políticas públicas en Belo Horizonte, Minas Gerais, Brasil, 1993-1997. Cad. Saude Publica 18(4):1087-1101, 2002.

12. Becher, H., et al. Risk factors of infant and child mortality in rural Burkina Faso. Bull. World Health Organ. 82(4):265-273, 2004.

13. Moore, D., et al. Determinants of health status and the influence of primary health care services in Latin America, 1990-98. Int. J. Health Plann. Manage. 18(4): 279-292, 2003.

14. Pan American Health Organization. Health analysis: Risks of dying and income inequalities. Epidemiol. Bull. 20(4):7-10, 1999.

15. Commission on Social Determinants of Health. A Conceptual Framework for Action on the Social Determinants of Health. 2007. www.who.int/social_determinants/ resources/csdh_framework_action_05_07.pdf (accessed July 2007).

16. Breilh, J. Epidemiología crítica: ciencia emancipadora e interculturalidad. Lugar Editorial, Buenos Aires, 2003.

17. Shandra, J. M., et al. Dependency, democracy, and infant mortality: A quantitative, cross-national analysis of less developed countries. Soc. Sci. Med. 59(2):321-333, 2004.

18. Franco, A., Alvarez-Dardet, C., and Ruiz, M. T. Effect of democracy on health: Ecological study. BMJ 329:1421-1423, 2004.

19. Navarro, V., and Shi, L. The political context of social inequalities and health. Int. J. Health Serv. 31(1):1-21, 2001.

20. UNICEF. Orphan Programming in Zambia: Developing a Strategy for Very Young Children in Zambia. 1998. www.harare.unesco.org/hivaids/webfiles/Electronic\%20 Versions/OrphanprogramminginZambia.doc (accessed April 2006).

21. Coburn, D. Beyond the income inequality hypothesis: Class, neo-liberalism, and health inequalities. Soc. Sci. Med. 58(1):41-56, 2004.

22. Whitehead, M., and Drever, F. Narrowing social inequalities in health? Analysis of trends in mortality among babies of lone mothers (abridged version 1). BMJ 318:908-912, 1999. 


\section{2 / Palma-Solis et al.}

23. Kawachi, I., et al. Social capital, income inequality, and mortality. Am. J. Public Health 87(9):1491-1498, 1997.

24. Shaw, C., et al. Do social and economic reforms change socioeconomic inequalities in child mortality? A case study: New Zealand 1981-1999. J. Epidemiol. Community Health 59(8):638-644, 2005.

25. Siddiqi, S., et al. Pakistan's maternal and child health policy: Analysis, lessons and the way forward. Health Policy 69(1):117-130, 2004.

26. Mankiw, N. G. Principios de macroeconomía. McGraw-Hill, Madrid, 1998.

27. Williamson, J. What Washington means by policy reform. In Latin American Adjustment: How Much Has Happened? ed. J. Williamson. Peterson Institute for International Economics, Washington, DC, 1990.

28. Bernal-Meza, R. El consenso de Washington. Meridiano 47. Boletim de Análise de Conjuntura em Relações Internacionais 25:12-16, 2002.

29. Williamson, J. A Short History of the Washington Consensus. Paper commissioned by Fundación CIDOB for the conference From the Washington Consensus towards a New Global Governance, Barcelona, 2004. www.iie.com/publications/papers/ williamson0904-2.pdf (accessed July 2007).

30. Kalmanovitz, S. Neoliberalismo e intervencionismo: sus fuentes y razones. Revista de Estudios Sociales 1:1-6, 1998.

31. Navarro, V. Neoliberalism, "globalization," unemployment, inequalities, and the welfare state. Int. J. Health Serv. 28:607-682, 1998.

32. United Nations. United Nations Millennium Declaration, 2000. A/RES/55/2. U.N. General Assembly, New York, 2000.

33. United Nations. Resources required to finance the Millennium Development Goals. In UN Millennium Project, 2005. Investing in Development: A Practical Plan to Achieve the Millennium Development Goals. Communications Development, Washington, DC, 2005.

34. Sachs, J., and McArthur, J. The Millennium Project: A plan for meeting the Millennium Development Goals. Lancet 365:347-353, 2005.

35. Lawn, J. E., Cousens, S., and Zupan, J. 4 million neonatal deaths: When? Where? Why? Lancet 365:891-900, 2005.

36. Horton, R. The health of peoples: Predicaments facing a reasoned utopia. Int. J. Health Serv. 33:543-568, 2003.

37. Navarro, V., et al. The importance of the political and the social in explaining mortality differentials among the countries of the OECD, 1950-1998. Int. J. Health Serv. 33:419-494, 2003.

38. Labonte, R., and Schrecker, T. Committed to health for all? How the G7/G8 rate. Soc. Sci. Med. 59:1661-1676, 2004.

39. World Health Organization. World Health Report Core Health Indicators. 2003. www3.who.int/whosis/core/core_select_process.cfm (accessed October 2003).

40. United Nations. Death rates specific for age, sex, and urban/rural residence: 19481997. Demographic Yearbook System. 2004. http://unstats.un.org/unsd/demographic/ products/indwm/ww2005/tab3b.htm (accessed February 2005).

41. United Nations. National accounts main aggregates database. Statistical Database. 2004. http://unstats.un.org/unsd/snaama/resultsBreak.asp?Slevel=1\&Cseries=Code14 $\&$ Year=2003\%2C2004\&IndCount=8\&Selection=basic (accessed June 2005). 
42. World Bank. Data Query System. 2004. http://devdata.worldbank.org/hnpstats/ (accessed January 2006).

43. World Bank. Economic Growth Research. 2002. www.worldbank.org/research/ growth/dddeisqu.htm (accessed February 2004).

44. International Data Base. Population and Household Economic Topics. 2002. www. census.gov/cgi-bin/ipc/idbsprd (accessed September 2003).

45. Freedom House. Freedom in the World Country Ratings 1972-2004. 2004. www. freedomhouse.org/ratings/allscores2005.xls (accessed April 2004).

46. Moser, K. A., Leon, D. A., and Gwatkin, D. R. How does progress towards the child mortality Millennium Development Goal affect inequalities between the poorest and the less poor? Analysis of demographic and health survey data. BMJ 331:1180-1182, 2005.

47. Franco-Giraldo, A., Palma, M., and Alvarez-Dardet, C. The effect of structural adjustment on health conditions in Latin America and the Caribbean, 1980-2000. Rev. Panam. Salud Pública 19(5):291-299, 2006.

48. Chung, H., and Muntaner, C. Welfare state matters: A typological multilevel analysis of wealthy countries. Health Policy 80(2):328-339, 2007.

49. Filmer, D., and Pritchett, L. The impact of public spending on health: Does money matter? Soc. Sci. Med. 50:1517-1518, 2000.

50. Van der Gaag, J., and Barham, T. Health and health expenditures in adjusting and non-adjusting countries. Soc. Sci. Med. 46:995-1009, 1998.

51. Adam, T., et al. Cost effectiveness analysis of strategies for maternal and neonatal health in developing countries. BMJ 31:1107-1112, 2005.

52. Edejer, T., et al. Cost effectiveness analysis of strategies for child health in developing countries. BMJ 331:1177, 2005.

53. Bambra, C., Fox, D., and Scott-Samuel, A. Towards a politics of health. Health Promot. Int. 20:187-193, 2005.

54. Navarro, V., et al. Politics and health outcomes. Lancet 368:1033-1037, 2006.

Direct reprint requests to:

Marco Antonio Palma-Solís

Facultad de Medicina de la Universidad Autónoma de Yucatán

Avenida de los Itzaes no. 498

Mérida, Yucatán

México CP 97200

e-mail: solis@uady.mx 